\title{
O Ensino da Ética nos Cursos de Graduação da Área de Saúde
}

\author{
Teaching Ethics in Undergraduate Health \\ Courses
}

\author{
Larissa Arbués Carneiro \\ Celmo Celeno Porto ${ }^{I I}$ \\ Soraya Bianca Reis Duarte ${ }^{I I I}$ \\ Neuma Chaveiro ${ }^{I V}$ \\ Maria Alves Barbosa ${ }^{I I}$
}

\section{PALAVRAS-CHAVE}

- Ensino.

- Ética.

- Ensino Superior

- Saúde.

\section{KEYWORDS \\ - Teaching \\ - Ethics \\ - Higher Education \\ - Health.}

Recebido em: 17/04/2009

Reencaminhado em: 23/10/2009

Aprovado em: 26/01/2010

REVISTA BRASILEIRA DE EDUCAÇ̄̃o MÉDICA

\footnotetext{
'Universidade Federal de Goiás, Goiânia, GO, Brasil; Secretaria Municipal de Saúde de Goiânia, Goiânia, GO, Brasil.

II Universidade Federal de Goiás, Goiânia, GO, Brasil.

III Universidade Federal de Goiás, Goiânia, GO, Brasil; Instituto Federal de Educação, Ciência e Tecnologia de Goiás, Goiânia, GO, Brasil.

${ }^{I V}$ Universidade Federal de Goiás, Aparecida de Goiânia, Goiânia, GO, Brasil.
}

This study provides an analysis of Brazilian articles on the teaching of ethics in undergraduate health courses from January 1997 to January 2009, using a search in the Virtual Health Library (VHL). Twenty-six articles met the inclusion criteria. The health fields receiving the main emphasis were medicine (19), nursing (5), and psychology and dentistry (1 each). Using content analysis, three thematic categories were identified: theoretical and philosophical reflections; pedagogical and methodological issues; and evaluation of the teaching of ethics. The main factors that influenced the learning of ethics were time of exposure to the course content and a crosscutting approach to ethics in the various other course disciplines. The study also highlighted the use of active methodologies and the professor's ethical background and attitude. Given current changes in education, technological and scientific progress, and the field of bioethics itself, it is necessary to discuss how ethics is taught in the health professions. 


\section{INTRODUÇÃO}

"Virtude é coisa que se ensina?". O personagem-título Menon, de Platão, inicia o diálogo com Sócrates a partir da questão se a virtude é fruto do ensino, adquirida pela experiência ou inerente à natureza dos homens ${ }^{1}$. O tema da "virtude", que desperta interesse desde a filosofia antiga, é definido por Aristóteles como uma disposição de caráter, a qual se distingue em duas "espécies": intelectual, dada por meio do ensino, e moral, adquirida pelo hábito².

A moral, diferentemente, se caracteriza como um conjunto de normas que regulam o comportamento social no sentido de garantir a ordem. São inculcadas nos indivíduos de forma que estes as reconheçam como parte de seus princípios e valores, seguindo-as de forma consciente e livre. Elas estão vinculadas aos interesses vigentes e, portanto, sujeitas a transformações segundo a época e a sociedade ${ }^{3}$.

Por sua vez, a ética reflete-se em condutas e normas resultantes do exercício da razão, da crítica ${ }^{4}$ e estaria vinculada, segundo Cohen e Segre ${ }^{5}$, a três pré-requisitos: consciência, autonomia e coerência. O conceito de ética supera, portanto, a ideia de um conjunto de normas, pressupondo reflexão e decisão, devendo ser compreendido contextualmente, porque também está sujeito às transformações da sociedade e da relação do homem com o ambiente ${ }^{6}$.

Instituídas socialmente, as profissões seguem normas e regras conexas ao seu exercício. A deontologia aí se insere. Tem caráter legal, pois se refere ao conjunto de deveres que o profissional tem que seguir em suas atividades. Por muito tempo, tal modelo foi a base do ensino da ética nos cursos de saúde e, apesar de importante, tem se mostrado insuficiente, uma vez que os códigos de conduta não têm acompanhado a contento as transformações ocorridas na sociedade ${ }^{7}$.

Cada vez mais, o mundo vem sofrendo mudanças intensas. Em especial a partir das grandes guerras, foram presenciadas violações dos direitos humanos e avanços científicos e tecnológicos sem precedentes, que despertaram a atenção para a necessidade de diretrizes e padrões que garantissem os princípios éticos, destacando-se:

- Código de Nuremberg (1947), resultado das discussões e julgamentos no Tribunal de Nuremberg, após a $2^{\mathrm{a}}$ Guerra Mundial;

- Declaração dos Direitos do Homem (1948), documento da Organização das Nações Unidas;

- Declaração de Helsinque (1964 e versões posteriores de 1975, 1983, 1989, 1996, 2000 e 2008);

- Relatório Belmont (1978), que definiu princípios éticos norteadores de pesquisas com seres humanos;
- Resolução no 196 de 10 de outubro de 1996, do Conselho Nacional de Saúde, que regulamentou a pesquisa com seres humanos no Brasil.

No cenário de mudanças nos direitos humanos e nas ciências, surge a bioética. Para Van Resselaer Potter, o criador deste neologismo, ela se configura como a ética da sobrevivência, da vida e do ser vivo ${ }^{8}$. Caracteriza-se por seus aspectos filosófico, científico e sociopolítico?

Estiveram presentes em seu surgimento o avanço tecnológico e dos direitos individuais, a influência do multiculturalismo na sociedade e as mudanças na relação médico-paciente. Esta nova abordagem da ética se relaciona à complexidade e à possibilidade de abertura para contribuições de diversas disciplinas e discussão mais ampliada com a sociedade ${ }^{8}$.

A bioética configura-se como um campo da ética aplicada que mais tem avançado e vem sendo utilizado como instrumento no processo de "discussão, aprimoramento e consolidação das democracias, das cidadanias, dos direitos humanos e da justiça social" (p. 126). Em especial a partir do movimento de estudiosos latino-americanos, atualmente adquiriu um caráter mais social e de intervenção em questões cada vez menos individuais e mais públicas ${ }^{10}$.

Diante deste novo contexto, deve-se partir do pressuposto de que a discussão sobre a ética é essencial no campo da assistência à saúde e da pesquisa. Porto ${ }^{11}$ ilustra a importância da ética com a metáfora matemática para a arte clínica representada por $\mathbf{A C}=\mathrm{E}\left[\mathrm{MBE}+(\mathbf{M B V})^{2}\right]$, em que "E" significa ética; "MBE", Medicina Baseada em Evidências; e "MBV", Medicina Baseada em Vivências. Como se vê, o elemento de destaque é a ética, evidenciando que esta dá o verdadeiro sentido à arte clínica, ou seja, a qualquer ato dos profissionais de saúde. Pode-se supor, nesse sentido, que a ética funcionaria como o eixo norteador da arte de "cuidar do outro", portanto, tema imprescindível na formação acadêmica.

No Brasil, o interesse pela discussão sobre o ensino da ética, em especial nos cursos de Medicina, tem crescido nos últimos anos. Na Faculdade de Medicina da Universidade Federal de Goiás (UFG), por exemplo, uma das primeiras tentativas de introdução desta discussão foi a criação de um Código de Ética para o estudante de Medicina em 1976, que foi estruturado a partir do Código de Ética Médica por uma comissão presidida pelo professor Celmo Celeno Porto, então chefe do Departamento de Clínica Médica e regente da disciplina de Semiologia Clínica, responsável pelo ensino-aprendizagem da relação médico-paciente.

A proposta, de caráter normativo, apesar de ter sido adotada em diversas faculdades de Medicina do Brasil, na UFG foi abandonada sem ser avaliada. Após certo tempo, perce- 
beu-se que a aprendizagem seria mais efetiva se baseada em princípios bioéticos. Considerou-se que em todo encontro do estudante com um paciente era possível questionar a conduta ética a partir dos princípios bioéticos seguindo o modelo de Beauchamp e Childress.

Mesmo em meio à discussão de que o modelo principialista atualmente não responde mais às necessidades da educação médica em bioética ${ }^{7}$, naquela época esta estratégia tornou-se parte da metodologia de ensino da disciplina de Semiologia Clínica e despertou grande interesse dos estudantes.

Atualmente, um terceiro modelo de bioética vem ocupando espaço. Chamado de deliberativo, tem caráter dialógico, inspirado na maiêutica socrática. Diante de um dilema ético, todos os envolvidos participam ativa e reflexivamente em direção a soluções razoáveis e prudentes ${ }^{7}$. Assim, no ambiente acadêmico, pode-se concordar com Munõz ${ }^{12}$ quando este afirma que "ética não se ensina, se discute" (p. 221), compreendendo que o processo de ensino-aprendizagem deve se dar por meio do debate dos temas a partir da prática e com todos os sujeitos envolvidos.

Alguns estudos avaliaram de forma abrangente a situação do ensino em bioética. Em 1985, Souza e Dantas constataram que havia poucas publicações na área, quase todas relacionadas à deontologia, concluindo que havia pouco interesse na área da ética médica ${ }^{13}$. No entanto, no mesmo ano, um relatório do Conselho Federal de Medicina mostrou que 56 escolas médicas, entre 58 pesquisadas, possuíam deontologia ou ética no currículo, havendo certo consenso entre os docentes de que as disciplinas deveriam ser ensinadas em todas as fases da formação ${ }^{14}$.

O ensino da ética foi novamente avaliado numa pesquisa publicada em 2003, realizada em 103 cursos de Medicina no Brasil, que evidenciou que a ética estava presente no currículo de $100 \%$ dos cursos. No entanto, os autores avaliaram que não havia mudanças significativas nos dez anos anteriores, mas apontaram uma tendência para melhorias ${ }^{15}$.

Mais recentemente, uma revisão sistemática realizada a partir de três artigos originais sobre o ensino de deontologia, ética e bioética em escolas médicas brasileiras revelou que nos últimos 30 anos houve pouco avanço na estrutura organizacional e educacional dos cursos de ética e bioética. Concluiu-se que havia poucos docentes exclusivos, pequena oferta de disciplinas específicas na área, assim como baixa carga horária ${ }^{16}$.

Considerando a ética um requisito essencial na chamada arte clínica, em especial neste momento, em que acompanhamos o avanço científico e tecnológico, questiona-se como a produção científica brasileira tem tratado o tema sob a ótica da educação, uma vez que esta também vem sofrendo modi- ficações a partir da proposta de reorientação do modelo de formação em saúde. Para tanto, estabelecemos como objetivo deste artigo analisar o ensino da ética nos cursos de graduação na área da saúde a partir de 1997 até 2009.

\section{METODOLOGIA}

Trata-se de uma revisão integrativa de artigos científicos sobre o ensino da ética nos cursos de saúde. O método é utilizado na abordagem da Prática Baseada em Evidências (PBE), na qual se realiza a avaliação crítica e a síntese das evidências científicas sobre o tema estudado. Ela permite conhecer de que forma o tema investigado tem sido trabalhado na atualidade ${ }^{17}$.

Por investigar estudos brasileiros, foi escolhido o período após a Resolução 196, de 10 de outubro de 1996, que regulamenta as pesquisas com seres humanos, e também o ano da Lei de Diretrizes e Bases da Educação Nacional (LDB), de 20 de dezembro de 1996, que propõe a substituição do currículo mínimo por diretrizes curriculares. Ambos são marcos legais que poderiam influenciar em mudanças do ensino da ética nos cursos de graduação. Foram selecionados artigos publicados de janeiro de 1997 a janeiro de 2009 no intuito de conhecer o estado da arte dos estudos na interface educação e ética.

Como a revisão integrativa trabalha com evidências, optou-se por privilegiar periódicos de divulgação científica. Assim, foi consultada a Biblioteca Virtual em Saúde (BVS), utilizando-se as bases de dados SciELO (Scientific Electronic Library Online), Medline (Medical Literature Analysis and Retrieval System Online) e Lilacs (Literatura Latino-Americana e do Caribe em Ciências da Saúde). Como descritores foram utilizados: ensino, ética e saúde.

Associando os descritores ensino e ética, foram encontradas 856 referências, sendo 57 na base de dados SciELO, 570 na Medline, 229 na Lilacs. Com os descritores ensino, ética e saúde foram encontradas 376 referências - na SciELO, 23, na Medline 263 e 90 na Lilacs.

Na primeira fase, realizou-se leitura dos títulos dos artigos, e, em caso de dúvida, seus resumos. Os textos completos não disponíveis nas bases de dados foram buscados nas páginas eletrônicas da revista. As publicações selecionadas obedeceram aos seguintes critérios de inclusão: origem brasileira; relação direta com os descritores; e ser de domínio público (disponibilidade on-line). Foram excluídos os artigos que não preencheram tais critérios, bem como textos repetidos, pois algumas revistas estão indexadas em mais de uma base de dados.

Ao final foram selecionados 26 artigos, analisados em relação a: área de produção, título do periódico e data de publicação. Por fim, foi utilizada a técnica da Análise de Conteúdo por Categoria Temática, referenciada por Bardin ${ }^{18}$. 
A técnica se aplica a discursos diretos e simples, como no caso dos textos científicos, e consiste em descobrir os núcleos de sentido cuja frequência ou presença faça sentido para o objetivo de análise escolhido.

As fases da análise consistem em: leitura flutuante do corpus de análise; e organização da análise por meio da exploração e tratamento do material, inferência e interpretação.

Esta última fase envolve a categorização temática, em que os núcleos de sentido são inferidos e interpretados, e comporta duas etapas: inventário, que isola os elementos relevantes; e classificação, que separa os elementos e organiza as mensagens. O resultado da técnica é o desmembramento do texto em unidades de registro (temas), que, no caso do presente estudo, foram agrupadas por critério semântico, ou seja, por seu significado.

\section{RESULTADOS E DISCUSSÃO}

A área com o maior número de publicações foi Medicina, com 19 artigos (73,08\%), seguida por Enfermagem, com 5 artigos $(19,23 \%)$, e pelas áreas de Psicologia e Odontologia, que contaram com 1 artigo (3,85\%) cada uma.

Este dado indica escassez de estudos sobre o tema nas profissões de saúde e maior participação da Medicina em publicações científicas nesta temática. Também chama a atenção a fragmentação do conhecimento, uma vez que nenhum dos artigos analisados foi elaborado numa perspectiva interdisciplinar.

A medicina foi a primeira profissão a se estruturar na área da saúde e acompanhou os diversos questionamentos éticos pelos quais a ciência e a humanidade passaram, bastando lembrar que o primeiro documento ético conhecido, o Juramento de Hipócrates (460 a.C. — 355 a.C.), foi escrito há mais de 2 mil anos. Por isso, não é de estranhar que o tema tenha se aprofundado mais na medicina que nas outras profissões da saúde. Outra possibilidade a considerar é a cultura de produção científica da profissão médica, que pode ser maior.

O periódico com maior número de artigos selecionados foi a Revista Brasileira de Educação Médica, com nove publicações, e em seguida a revista Bioética, que contou com cinco artigos. Duas outras revistas tiveram a frequência de dois artigos cada, e os demais periódicos tiveram frequência de um artigo por revista. A Tabela 1 relaciona a quantidade de artigos publicados por periódico.

O número de publicações foi maior no periódico especializado na educação médica, o que pode justificar a diferença em relação aos outros. Semelhante observação vale para a revista Bioética, voltada para a temática da ética e bioética, mas com as publicações praticamente concentradas no ano de 2002, quando publicou uma edição especial sobre educação e ética.
TABela 1

Relação da Quantidade de Artigos Encontrados por Periódico de Janeiro de 1997 a Janeiro de 2009

\begin{tabular}{lc}
\hline Periódico & $\begin{array}{c}\text { Quantidade } \\
\text { de Artigos }\end{array}$ \\
\hline Revista Brasileira de Educação Médica & 9 \\
Bioética & 5 \\
O Mundo da Saúde & 2 \\
Revista da Escola de Enfermagem USP & 2 \\
Acta Paulista de Enfermagem & 1 \\
Arquivos de Ciências da Saúde & 1 \\
Ciência \& Saúde Coletiva & 1 \\
Cogitare Enfermagem — UFPR & 1 \\
Interface - Comunicação, Saúde e Educação & 1 \\
Psicologia em Estudo - Maringá & 1 \\
Revista da Associação Médica Brasileira & 1 \\
Revista Brasileira de Enfermagem & 1 \\
\hline TOTAL & 26 \\
\hline
\end{tabular}

O período das publicações variou de agosto de 1997 a janeiro de 2009. Os anos de 2002 e 2008 contaram com o maior número de publicações, cinco cada ano, seguidos por 2009, com quatro publicações. Em 2006 e 2004 houve três publicações, em 2003 constaram duas, e nos anos de 1997, 2000, 2005 e 2007 uma publicação cada.

Para melhor compreensão desta temática, as publicações encontradas serviram como corpus para uma análise de conteúdo. Isto permitiu subdividir os achados em três categorias - reflexões teóricas e filosóficas; aspectos pedagógicos e metodológicos; avaliação da aprendizagem -, que possibilitam uma visão de conjunto sintetizada no Quadro 1.

\section{Reflexões Teóricas e Filosóficas}

Muitos autores ${ }^{9,15,16,19-25}$ se preocuparam em discorrer sobre os aspectos teóricos e filosóficos da ética. Temas como moral e ética surgiram no intuito de diferenciar e correlacionar os dois termos. E assim como termos relativos a valores, senso crítico e autonomia complementaram os textos $4,15,16,20,21-24$,

Moral é considerada um conjunto de regras, construído socialmente, que se segue para ser aceito em dada comunidade. A ética se diferencia, pois se refere à reflexão sobre a moral, portanto, dotada de senso crítico, pressuposições subjetivas e autonomia diante das decisões ${ }^{9,23}$.

Para Siqueira et al. ${ }^{26}$, somente o conhecimento dos aspectos morais e normativos é insuficiente. É necessário que o profissional em formação exercite sua capacidade crítica e de 


\section{QuADRO 1}

Categorias e Temas Emergentes a partir da Análise de Conteúdo da Produção Científica de Janeiro de 1997 a Janeiro de 2009 Referente ao Ensino da Ética

\begin{tabular}{|l|l|}
\hline Categorias & Temas \\
\hline$\bullet$ Reflexões teóricas e filosóficas & - moral/ética/valores \\
& - senso crítico \\
& - autonomia \\
& - crica como fator de humanização das relações \\
& - bioética como ativador de mudança \\
\hline - Aspectos pedagógicos e metodológicos currículo
\end{tabular}

decisão, superando o modelo estruturado em disciplinas específicas, muitas vezes dissociadas da vivência e interesse dos estudantes, e que não atende mais às necessidades de formação, que se propõe mais humanista e valoriza as relações ${ }^{4,21,23}$.

A prática mais humanizada pode levar a uma reflexão sobre a ética enquanto campo do cuidado. A partir de experiências de cuidado significativas, ou seja, que façam sentido para o estudante, é que é possível tornar a prática mais humana, solidária, autônoma e crítico-reflexiva ${ }^{27}$. Tais competências são essenciais para o profissional que se prepara para atuar na atenção em saúde, em especial no momento de questionamento do modelo biomédico.

A crise do modelo biomédico e o advento da bioética também compuseram a análise dos autores ${ }^{4,9,15,21,23,26}$. A ascensão do modelo biopsicossocial, que contempla a integralidade do homem e uma percepção complexa da realidade, se deu juntamente com a crítica ao modelo biomédico, caracterizado pelo que Luz denominou "paradigma da patologia", com foco na diagnose e na especialização ${ }^{28}$.

A emergência da bioética, como campo filosófico, científico e sociopolítico, tem como fator contribuinte a ascensão do modelo biopsicossocial ${ }^{9}$. Ela se configura como uma releitura da ética na saúde e se propõe como movimento transdisciplinar ${ }^{21}$, com a contribuição das mais diversas áreas do conhecimento.

A bioética integra tanto os saberes simbólicos quanto os científicos ${ }^{9}$, em que o conhecimento e os valores são usados em favor da vida. Por isso, para Potter, ela representa uma "ponte para o futuro", uma vez que alia conhecimento científico e valores humanos ${ }^{8}$. Para esse autor, a universidade, como lugar de busca da verdade, deve ter o papel de transmitir aos estudantes valores além de conhecimentos ${ }^{29}$.

O movimento de transformações no mundo das ciências, cenário do surgimento da bioética, está influenciando a educação. Nos últimos anos, em especial, têm-se realizado esforços no sentido da reorientação curricular nas graduações da área da saúde. Por isso, a organização curricular nos cursos de saúde também foi alvo de reflexão em alguns artigos ${ }^{16,20-24,27,30,31}$.

Segundo Lopes e Macedo ${ }^{32}$, resquícios de uma concepção funcionalista de ensino ainda influenciam a educação, e na área da saúde o modelo biomédico reforça esse modo de organização. O currículo fragmentado contribui para uma formação igualmente fragmentada, o que traz consequências para o ensino da ética na graduação.

Nesse sentido, a reforma curricular pode ser uma oportunidade para inserir a ética de forma integrada nos mais variados níveis da formação dos estudantes de graduação ${ }^{21}$. E, ainda, a reestruturação da universidade é apontada como um caminho para superar o modelo de formação especializado, que tem como algumas das consequências o descompromisso com os valores éticos, a fragmentação do conhecimento e o empobrecimento acadêmico ${ }^{29}$.

\section{Aspectos Pedagógicos e Metodológicos}

Alguns autores ${ }^{4,9,20-22,27,30,33-35}$ defendem a ética ou bioética como conteúdo transversal na formação, ou seja, sua abordagem nas 
diversas disciplinas. Contudo, na maioria das vezes, a ética é dada como disciplina independente, recebendo denominações como deontologia, ética e/ou bioética, ou compondo o programa da medicina legal, no caso do curso médico ${ }^{15,16,23}$.

O potencial da ética como eixo transversal na formação em saúde aplica-se especialmente no momento de crise do paradigma biomédico e na reestruturação curricular dos cursos de saúde. É importante investir na transdisciplinaridade das disciplinas do curso com o objetivo de colocar a serviço da sociedade profissionais que visem aprimorar, além de aptidões teórico-técnicas, o desenvolvimento de habilidades sociais e pessoais, incentivando a avaliação e o exercício da autocrítica permanentemente no processo natural das atividades de todas as disciplinas básicas e profissionais ${ }^{36}$.

A educação deve ser considerada um instrumento de reflexão acerca da realidade e, para isto, deve restaurar a concepção de complexidade. Nesse sentido, o modelo curricular por disciplinas tem influência na formação, e o ensino da ética neste sistema tradicional mostra-se insuficiente ${ }^{20,30}$.

Mais ainda, há casos em que os princípios éticos não estão contemplados de forma clara no currículo formal e mesmo nas diretrizes curriculares do curso, conforme aponta o estudo de Ferreira Neto e Penna ${ }^{24}$ que abordou a relação ética, clínica e diretrizes curriculares em um curso de Psicologia.

Algumas experiências e indicações em direção à integração da ética na graduação estão na utilização de metodologias ativas, como a aprendizagem baseada em problemas ${ }^{7,20,26,30} \mathrm{ou}$ problematização ${ }^{21,23}$, como instrumentos de construção do conhecimento nos cursos de saúde.

Gomes et al. ${ }^{9}$ realizaram um estudo em que foram avaliadas duas instituições que passaram por estruturação ou reestruturação curricular recente e que tinham como um dos eixos a aprendizagem baseada em problemas (Problem Based Learning - PBL). Revelou-se que em apenas uma das instituições a ética aparece de forma transversal no currículo, e os autores atribuem este dado ao modelo de ensino integrado adotado pela instituição. Contrariamente, na outra instituição, mesmo com metodologia semelhante, a ética está identificada em três disciplinas de semestres mais avançados, mas os autores argumentam maior diversidade no corpo docente da área de ética como fator positivo.

D'Avila questiona: “É possível ensinar ética médica em um curso formal curricular?"33 (p.115). Estendendo a questão a todos os cursos da saúde, é importante conhecer em que medida a forma de organização curricular influencia a aprendizagem ética. E mais, em que medida o currículo realiza mudanças significativas na educação para que esta atenda às demandas sociais ${ }^{9}$.
Erdmann et al. ${ }^{37}$ atentam para o fato de que, no ensino da ética, a mera mudança de recursos didáticos e pedagógicos não é suficiente. Devem ser considerados mais importantes métodos que envolvam a criatividade e a prática do diálogo que possibilitem a reflexão crítica do estudante.

Além da metodologia utilizada, outro fator para a aprendizagem da ética é a postura dos docentes, que deve incentivar a conduta ética ${ }^{16,22,33,35,38}$, ou seja, suas atitudes nas situações de ensino devem servir como exemplo para os estudantes. Contam muito atitudes que tenham o potencial de atrair, comprometer, apaixonar e despertar no estudante o melhor de $\mathrm{si}^{39}$. Nesse sentido, o foco do ensino volta-se mais para a aquisição de habilidades do que para a dimensão cognitiva.

Um dado importante do trabalho de Almeida et al. ${ }^{34}$ alerta para o fato de que, ao contrário do que se pode considerar ideal, ou seja, docentes que sejam exemplos de conduta ética, os estudantes podem ter sua formação moral prejudicada, uma vez que esses autores encontraram em seu estudo a alegação de estudantes identificando docentes como maus exemplos, com uma tendência crescente de contato com eles ao longo da graduação. Constatação semelhante foi encontrada em outro estudo em que $66 \%$ dos estudantes pesquisados informaram haver tido contato com professores considerados maus exemplos de conduta ${ }^{38}$. Deve-se observar que a conduta ética é base para qualquer docente, pois é papel de todo educador contribuir para a formação moral e ética dos estudantes ${ }^{4}$.

Para as disciplinas de ética, o docente deve ainda ter conhecimento sobre ciências humanas e sociais, nos campos da Filosofia, Pedagogia, Sociologia, Antropologia e Psicologia ${ }^{22,36}$. Entretanto, segundo estudo realizado com cursos de Medicina em $2003^{15}$, a maioria não possuía professores especializados em ética, e poucos deles eram da área das ciências humanas ou sociais.

\section{Avaliação da Aprendizagem}

A avaliação da aprendizagem da ética é tema pouco explorado. Poucos artigos ${ }^{20,24,25,34,40}$ se dedicaram a abordar esta temática. Tais estudos podem gerar subsídios para mudanças daquilo que está deficiente ou inadequado.

Para as avaliações foram utilizados métodos como entrevistas, questionários e uso de casos envolvendo situações relativas à ética, com avaliação das respostas dos estudantes.

Segundo o estudo de Ferreira Neto e Penna em $2006^{24}$ e Silva et al. em $2005^{40}$, ao longo do curso a dita sensibilidade ética tem uma tendência ascendente. Isto significa a capacidade do profissional de discernir questões que merecem considerações de conteúdo ético nas situações clínicas ${ }^{40}$. 
No estudo de Ferreira Neto e Penna ${ }^{24}$, por meio de questionários aplicados a estudantes de séries iniciais e finais de um curso de Psicologia, concluiu-se que, daqueles que cursavam o segundo período, 47,5\% associaram a ética à construção da postura e atitude profissional, enquanto $72 \%$ dos estudantes do décimo período fizeram esta associação.

Silva et al. ${ }^{40}$, baseados em estudo anterior realizado em Toronto, aplicaram questões em casos de decisão ética a estudantes de Medicina em cada ano de graduação. Os autores perceberam aumento da sensibilidade ética de acordo com o ano, com pequeno declínio no terceiro ano. No primeiro ano, a média de acertos foi de $18,3 \%$, e no sexto ano foi de $29,6 \%$. Os autores apontam estudo anterior de Hebert et al., em 1992, com resultados divergentes, em que, curiosamente, entre o segundo, terceiro e quarto anos houve diminuição da sensibilidade ética.

A pesquisa de Figueira et al. ${ }^{20}$ em um curso de Medicina corrobora o tema ao apontar que o maior tempo de exposição aos conteúdos de ética aumenta a possibilidade de aprendizagem, considerando-se a quantidade de acertos entre o primeiro $(13,97 \%)$ e o sexto ano $(16,77 \%)$ em um dos questionários. Os autores concluem ainda que não existe diferença significativa quando comparados diferentes modelos pedagógicos. Constatou-se nos resultados uma diferença entre média de acertos de 17,15\% para estudantes do método tradicional e $16,51 \%$ para o método PBL. Os resultados contrariam a afirmação de Gomes et al. ${ }^{9}$ de que a metodologia do curso pode influenciar a aprendizagem ética.

Uma pesquisa em faculdades de Medicina de São Paulo ${ }^{25}$ também indica a aprendizagem relacionada ao tempo de exposição. Nela, estudantes do sexto ano obtiveram percentual maior de acertos em questões sobre ética. No entanto, para somente $8,9 \%$ dos acadêmicos o curso de bioética foi responsável por alterações profundas no comportamento. $\mathrm{O}$ dado de que $57 \%$ dos estudantes não souberam diferenciar deontologia de bioética reforça o baixo impacto que a disciplina tem nos cursos médicos pesquisados.

Em estudo publicado em 2008, avaliando o interesse e conhecimento de estudantes e docentes em um curso de Medicina, Almeida et al. ${ }^{34}$ concluíram que tanto docentes quanto estudantes atribuem elevada importância à disciplina de ética. $\mathrm{E}$, ao avaliarem o conhecimento em ética por meio de questões sobre o Código de Ética Médica, encontraram uma média de acertos de $62,4 \%$ dos estudantes e $55,5 \%$ dos professores. Os primeiros, portanto, tiveram um desempenho melhor, embora tais médias tenham sido consideradas regulares pelos autores. Em estudo semelhante ${ }^{38}$, dados indicam média de acertos aproximada entre discentes e docentes, 5,5 e 5,6 respectivamente.
Assim mesmo, o dado contraria a afirmativa de Figueira et al. ${ }^{20}$ de que a aprendizagem ética está associada ao tempo de exposição aos conteúdos, partindo da suposição de que os docentes possuem mais tempo de prática clínica e contato com situações que envolvem decisões éticas.

É ao longo da graduação que o estudante aumenta sua prática clínica, que está intrinsecamente ligada à ética, pois é nela que os dilemas éticos afloram ${ }^{41}$. Nesta prática, o estudante já se depara com as implicações éticas da relação com o paciente, que ali se encontra em situação de vulnerabilidade. São essenciais o equilíbrio da proposta terapêutica com os interesses acadêmicos, respeito à autonomia, sigilo e estar em constante contato com o supervisor/professor no intuito de minimizar qualquer conflito que venha ferir a conduta ética e a relação terapêutica ${ }^{24,41}$.

Ao entrevistarem estudantes do último ano do curso de Psicologia que estavam no estágio clínico, Ferreira Neto e Pena apontam que estes têm na supervisão um meio de avaliar os dilemas éticos encontrados na prática, mesmo que não haja respostas prontas, uma vez que os casos são singulares. E, como o terapeuta é afetado pela prática clínica, a ética estaria ligada à complementaridade da formação teórica com a formação pessoal ${ }^{24}$.

Uma vez que as dimensões ética e clínica estão intrinsecamente ligadas, o estágio na clínica de ensino é um lugar apropriado para avaliar a capacidade de aplicar o que foi aprendido no nível cognitivo. É um momento que exige aplicação prática dos princípios éticos e que possibilita conhecer o comprometimento do estudante com sua profissão.

\section{CONCLUSÃO}

Foi realizada análise de artigos de publicação nacional entre janeiro de 1997 e janeiro de 2009, utilizando-se os descritores ensino, ética e saúde. Vinte seis artigos estavam de acordo com os critérios de inclusão e constatou-se que havia produções de apenas quatro profissões - Medicina, Enfermagem, Odontologia e Psicologia — dentre as 14 profissões da área da saúde.

Os dados apontam números ainda tímidos em relação ao volume de publicações em saúde. Percebeu-se um predomínio absoluto de publicações de Medicina, em sua maioria concentradas em duas revistas, e não houve publicações de caráter interdisciplinar sobre a temática.

A análise de conteúdo dos artigos revelou três categorias temáticas. Na primeira categoria, houve dispersão entre os temas: moral, ética e valores; a ética como senso crítico, autonomia e ética como fator de humanização das relações. A crise do modelo biomédico, a ascensão do modelo biopsicossocial e o surgimento da bioética apareceram como fatores ativadores 
de mudanças na educação. E, ainda, foram discutidas as mudanças na organização curricular como influência no cenário da educação e no ensino da ética.

A segunda categoria, aspectos pedagógicos e metodológicos, revelou temas como a importância da transversalidade no ensino da ética; a influência da estrutura curricular e diretrizes no ensino, com destaque para a discussão sobre as metodologias ativas. Além disso, a importância da aproximação da ética com as ciências humanas e do docente como modelo. Conclui-se que os modelos metodológicos, assim como a formação e a atitude do docente são essenciais no processo de aprendizagem.

Avaliação da aprendizagem como categoria revelou, a partir de estudos na área, que o aumento da sensibilidade ética está relacionado ao tempo de exposição do aluno aos conteúdos de ética. No entanto, alguns estudos constatam que o conhecimento dos docentes, supostamente expostos há mais tempo a conteúdos e situações de conflitos éticos, se equipara ao dos estudantes. Nesta categoria, destaca-se também a importância do ensino de modo transversal durante o curso e ainda a relevância da ética aplicada à clínica de ensino.

Considerando as limitações do presente estudo no que se refere aos critérios de inclusão dos artigos e à acessibilidade a fontes, são necessárias investigações mais detalhadas, como as de caráter longitudinal, que acompanhem a relação do estudante com a ética durante a graduação e depois dela. E cabe ainda questionar se o modelo de ensino é realmente determinante na aprendizagem ética.

A escassez de estudos na área aponta a necessidade de criar linhas de pesquisa na interseção entre educação e ética, uma vez que, no momento da aprendizagem da prática clínica, questões de ordem ética são comuns, e a possibilidade de discutir o tema pode ajudar no preparo do estudante para uma atuação profissional mais responsável e humanizada.

Diante do contexto de mudanças no ensino superior, do avanço científico e tecnológico e do próprio campo da ética e bioética, o tema merece mais atenção no sentido de se conhecer como os cursos de graduação vêm acompanhando essas mudanças e de que forma isto tem se aplicado e influenciado a educação na área da saúde.

\section{REFERÊNCIAS}

1. Platão. Mênon: Texto estabelecido e anotado por Jonh Burnet. Rio de Janeiro: Ed. PUC-Rio, Loyola; 2001.

2. Aristóteles. Ética a Nicômaco. São Paulo: Abril Cultural; 1979. v. 2. (Coleção Os Pensadores).

3. Vázquez AS. Ética. $20^{\underline{a}}$ ed. Rio de Janeiro: Civilização Brasileira; 2000. Moral e História. p 37-60.
4. Rego S, Gomes AP, Siqueira-Batista R. Bioética e Humanização como Temas Transversais na Educação Médica Rev Bras Educ Med [periódico na internte]. 2008 [acesso em 12 jan. 2009]; 32(4):482-491. Disponível em: http:// www.scielo.br/scielo.php?script=sci_arttext\&pid=S0100$-55022008000400011 \& \operatorname{lng}=\mathrm{pt} \& \mathrm{nrm}=\mathrm{iso} \& \mathrm{t} \operatorname{lng}=\mathrm{pt}$

5. Cohen C, Segre M. Breve Discurso sobre Valores, Moral, Eticidade e Ética. Bioética [periódico na internet]. 1994 [acesso em 27 out. 2008]. 2(1):19-24. Disponível em: http:/ / www.portalmedico.org.br/bioetica/index.php?seleciona Revista $=3 \&$ opcao $=$ revista

6. Siqueira BP. A ética do estudante de medicina. In: Assad JE, Liberal HSP, Freitas Jr HL, org. Desafios Éticos. Brasília: Conselho Federal de Medicina; 1993. p.93-6.

7. Siqueira JE. O ensino da ética no curso de medicina. Mundo da Saúde [periódico na internet]. 2009 [acesso em 18 jun 2009];33(1):8-20 Disponível em: www.saocamilo-sp. $\mathrm{br} / \mathrm{pdf} /$ mundo_saude/66/8a20.pdf

8. Durand G. Introdução Geral à Bioética: história, conceitos e instrumentos. São Paulo: Ed. Centro Universitário São Camilo, Loyola; 2003.

9. Gomes AMA, Moura ERFM, Amorim RF. O Lugar da ética e bioética nos currículos de formação médica. Rev Bras Educ Med [periódico na internet]. 2006 [acesso em 18 abr. 2008]; 30(2):56-65. Disponível em: http://www. scielo.br/scielo.php?script=sci_arttext\&pid=S0100$-55022006000200008 \& \operatorname{lng}=$ pt\&nrm=iso\&tlng=pt

10. Garrafa V. Da bioética de princípios a uma bioética interventiva. Bioética [periódico na internet]. 2005 [acesso em 18 abr. 2008]: 13(1):125-34. Disponível em: http://www. portalmedico.org.br/bioetica/index.php?opcao=revista\& selecionaRevista $=25 \#$

11. Porto CC. O outro lado do Exame Clínico na medicina moderna. Arq Bras Cardiol. 2006;87 (4):124-8.

12. Munõz DR. O Ensino da Bioética nas Escolas Médicas. In: Pessini L, Barchifontaine CP, org. Bioética e Longevidade Humana. São Paulo: Ed. Centro Universitário São Camilo, Loyola; 2006. p. 217-35.

13. Souza EG, Dantas F. O ensino da deontologia nos cursos de graduação médica no Brasil. Rev Bras Educ Med. 1985;9(1):7-9.

14. Gomes CM. O Atual Ensino da Ética para os Profissionais de Saúde e seus Reflexos no Cotidiano do Povo Brasileiro. Bioética [periódico na internet]. 1996 [acesso em 27 out. 2008]; 4(1):53-64. Disponível em: http://www.portalmedico.org. $\mathrm{br} /$ bioetica/index.php?selecionaRevista $=7 \&$ opcao=revista

15. Munõz D, Munõz DR. O ensino da ética nas faculdades de medicina do Brasil. Rev Bras Educ Med. [periódico na 
internet]. 2003 [acesso em 19 abr. 2008]; 27(2):114-24. Disponível em: http:/ / www.educacaomedica.org.br/UserFiles/File/2003/volume27\%202/ensino_da_etica.pdf

16. Dantas F, Sousa EG. Ensino da Deontologia, Ética Médica e Bioética nas Escolas Médicas Brasileiras: uma Revisão Sistemática. Rev Bras Educ Med. [periódico na internet]. 2008 [acesso em 12 jan. 2009];32(4):507-17. Disponível em: http:/ / www.scielo.br/scielo.php?script=sci_arttext\&pid=S0100$-55022008000400014 \& \operatorname{lng}=$ pt\&nrm=iso\&tlng=pt

17. Mendes KDS, Silveira RCCP, Galvão CM. Revisão Integrativa: método de pesquisa para incorporação de evidências na saúde e na enfermagem. Texto Contexto-Enferm. [periódico na internet]. 2008 [acesso em 18 jun 2009]; 17(4):758-64. Disponível em: http://www.scielo. br / scielo.php?pid=S0104-07072008000400018\&script=sci_ abstract\&tlng=e

18. Bardin, L. Análise de conteúdo. Lisboa: Edições 70; 1977.

19. Paschoal AS, Mantovani MF, Polak YNS. A importância da ética no ensino de enfermagem. Cogitare Enferm. [periódico na internet]. 2002 [acesso em 18 abr. 2008]. 7(2):1-7. Disponível em: http://ojs.c3sl.ufpr.br/ojs2/index.php/ cogitare/issue/view/190

20. Figueira EJG, Cazzo E, Tuma P, Silva Filho CR, Conterno LO. Apreensão dos tópicos de ética médica no ensino-aprendizagem de pequenos grupos. Comparando aprendizagem baseada em problemas com o modelo tradicional. Rev Assoc Med Bras. [periódico na internet]. 2004 [acesso em 19 abr. 2008]; 50(2):133-41. Disponível em: http:/ / www.scielo.br/pdf/ramb/v50n2/20772.pdf

21. Athanazio RA, Lemos KM, Fonseca DC, Cunha MS, Braghiroli MIM, Almeida AM, et al. Academética; um novo método de estudo continuado sobre ética médica e bioética. Rev Bras Educ Med. [periódico na internet]. 2004 [acesso em 18 abr. 2008]; 28(1):73-8. Disponível em: http:/ / www.educacaomedica.org.br/UserFiles/File/2004/volume28_1/academetica.pdf

22. Ferreira HM, Ramos LH. Diretrizes curriculares para o ensino da ética na graduação em enfermagem. Acta Paul Enferm [periódico na internet]. 2006. [acesso em 19 abr. 2008]; 19(3):328-31. Disponível em: http://www. scielo.br/scielo.php?script=sci_arttext\&pid=S0103$-21002006000300012 \& \operatorname{lng}=p t$

23. Siqueira JE, Eisele RL. O Ensino da Ética no Curso de Medicina. Rev Bras Educ Med [periódico na internet]. 2000. [acesso em 18 abr. 2008]; 24(1):22-6. Disponível em: http:/ / www.educacaomedica.org.br

24. Ferreira Neto JL, Penna LMD. Ética, clínica e diretrizes: a formação do psicólogo em tempos da avaliação de cursos. Psicol Estud. [periódico na internet]. 2006 [acesso em 19 abr. 2008]; 11(2):381-90. Disponível em: http:/ / www.scielo.br/scielo.php?script=sci_arttext\&pid=S1413-73722006000200017\&lng=es\&nrm=iso\&tlng=es

25. Oliveira GB, Guaiumi TJ, Cipullo JP. Avaliação do ensino de Bioética nas faculdades de medicina do estado de São Paulo. Arq Ciênc Saúde [periódico na internet]. 2008 [acesso em 18 jun 2009]; 15(3):125-31. Disponível em: http:/ / www. cienciasdasaude.famerp.br/racs_ol/vol-15-3/v15-3.htm

26. Siqueira JE, Sakai MH, Eisele RL. O ensino da ética no curso de medicina: experiência da Universidade Estadual de Londrina (UEL). Bioética [periódico na internet]. 2002. [acesso em 01 mai. 2008]; 10(1):85-95. Disponível em: http:/ / www.portalmedico.org.br/revista/bio10v1.htm

27. Silva RM, Gurgel AH, Moura ERF. Ética no processo ensino-aprendizagem em enfermagem obstétrica. Rev Esc Enferm USP [periódico na internet]. 2004. [acesso em 01 maio 2008]; 38(1):28-36. Disponível em: http:// www.scielo.br/scielo.php?script=sci_arttext\&pid=S0080$-62342004000100004 \& \operatorname{lng}=p t \& n r m=i s o \& t \operatorname{lng}=p t$

28. Luz MT. Novos Saberes e Práticas em Saúde Coletiva: Estudo sobre Racionalidades Médicas e Atividades Corporais. 2a Ed. São Paulo: Hucitec; 2005.

29. Siqueira JE. Universidade e educação em bioética. In: Pessini L, Barchifontaine CP, org. Bioética e Longevidade Humana. São Paulo: Ed. Centro Universitário São Camilo, Loyola; 2006. p. 183-94.

30. Siqueira JE. O ensino da Bioética no curso médico. Bioética [periódico na internet]. 2003. [acesso em 01 maio 2008]; 11(2):33-42. Disponível em: http://www.portalmedico. org.br/revista/bio11v2.htm

31. Grisard N. Ética Médica e Bioética: a disciplina em falta na graduação médica. Bioética [periódico na internet]. 2002. [acesso em 01 maio 2008]; 10(1):97-114. Disponível em: http:/ / www.portalmedico.org.br/revista/bio10v1.htm

32. Lopes AC, Macedo E, org. Currículo: debates contemporâneos. São Paulo: Cortez; 2002. v. 2.

33. D'Avila RL. É possível ensinar Ética Médica em um curso formal curricular? Bioética [periódico na internet]. 2002 [acesso em 01 mai 2008]; 10(1):115-26. Disponível em: http:/ / www.portalmedico.org.br/revista/bio10v1.htm.

34. Almeida AM, Bitencourt AGV, Neves NMBC, Neves FBCS. Lordelo MR, Lemos KM et al. Conhecimento e Interesse em Ética Médica e Bioética na Graduação Médica. Rev Bras Educ Med. [periódico na internet]. 2008. [acesso em 12 jan. 2009]; 32(4):437-44. Disponível em: http:/ / www.scielo.br/scielo.php?script=sci_arttext\&pid=S0100$-55022008000400005 \& \operatorname{lng}=$ pt\&nrm $=$ iso\&tlng $=$ pt 
35. Serodio AMB, Almeida JAM. Situações de conflitos éticos relevantes para a discussão com estudantes de Medicina: uma visão docente. Rev Bras Educ Med. [periódico na internet]. 2009. [acesso em 18 jun 2009]; 33(1):55-62. Disponível em: http:/ / www.scielo.br/scielo.php?script=sci_ abstract\&pid=S0100-55022009000100008\&tlng=pt

36. Sá Jr. LSM. Ética do professor de medicina. Bioética. [periódico na internet]. 2002 [acesso em 01 maio 2008]; 10(1):4984. Disponível em: http://www.portalmedico.org.br/revista/bio10v1.htm.

37. Erdmann AL. Educação em bioética: desafios para a formação crítico-criativa dos profissionais de enfermagem. In: Pessini L, Barchifontaine CP, org. Bioética e Longevidade Humana. São Paulo: Ed. Centro Universitário São Camilo, Loyola; 2006. p. 237-50.

38. Vieira PSPG, Neves NMBC. Ética médica e bioética no curso médico sob o olhar dos docentes e discentes. Mundo da Saúde [periódico na internet]. 2009. [acesso em 18 jun 2009]; 33(1):1-25. Disponível em: www.saocamilo-sp.br/ pdf/mundo_saude/66/21a25.pdf

39. Valls LM. Da Ética à Bioética. Petrópolis: Vozes; 2004.

40. Silva JTN, Miranda D, Marcolino JAM, Muñoz DR. Medida da Sensibilidade Ética em Estudantes da Medicina: um Estudo na Faculdade de Ciências Médicas da Santa Casa de São Paulo. Rev Bras Educ Med. [periódico na internet]. 2005 [acesso em 18 abr. 2008]; 29(2):103-9. Disponí- vel em: http://www.educacaomedica.org.br/UserFiles / File/2005/volume29_2/medida_da_sensibilidade.pdf.

41. Gonçalves ER, Verdi MIM. Os problemas éticos no atendimento a pacientes na clínica odontológica de ensino. Ciênc Saúde Colet. [periódico na internet]. 2007 [acesso em 18 abr. 2008]; 12(3):755-64. Disponível em: http:/ / www.scielo.br/scielo.php?script=sci_arttext\&pid=S1413$-81232007000300026 \& \operatorname{lng}=\mathrm{pt} \& \mathrm{nrm}=\mathrm{iso} \& \mathrm{t} \operatorname{lng}=\mathrm{pt}$

\section{CONTRIBUIÇÃO DOS AUTORES}

Todos os autores contribuíram na concepção e desenho do estudo, aquisição de dados, análise e interpretação de dados, elaboraram a versão inicial do artigo, revisão crítica para conteúdo intelectual significativo e aprovaram a versão encaminhada para publicação

\section{CONFLITO DE INTERESSES}

Declarou não haver.

\section{ENDEREÇO PARA CORRESPONDÊNCIA}

Larissa Arbués Carneiro

Rua Longitudinal, 75 - apto 104C

St. Leste Vila Nova - Goiânia

CEP 74633-300 - GO

E-mail: larissa@arbues.com.br 